\title{
Research on the Innovative Teaching Method of Chinese Language and Literature Major under the Open Education Mode
}

\author{
Hui Zheng \\ School of Humanities and Social Sciences, Panzhihua University, Panzhihua 617000, China \\ zhenghuigreat@163.com
}

\begin{abstract}
The Chinese language, literature and literature majors have sent a number of applied high-level talents that inherit the Chinese language and culture, the comprehensive development of morality and intelligence, and the teaching of Chinese language at the grassroots level. They are also called "humanities" applied talents. From the perspective of quality, the humanistic talents have the ability to apply Chinese language and literature knowledge flexibly, and bear the heavy responsibility of inheriting Chinese language and literature and writing. They have the charisma of "being poetry and poetry and self-satisfaction", gentle and elegant, and positive and positive. From the analysis of talents, they have strong verbal expression, written expression and writing ability, and have unique appreciation ability for literature and culture. In order to achieve the goal of delivering high literary talents to the society, the open education model has been fully opened. However, limited by the form of education and content restrictions, it is impossible to guarantee that every student can truly learn something. To this end, it is necessary to innovate the innovative teaching methods of Chinese language and literature majors under the open education model, combining modern reading mode and diversified reading [1]-[4]. Channels, in line with the society and the market, enrich the form of teaching so that each student can benefit from the teaching model.
\end{abstract}

Keywords: Open education model, Chinese language and literature, Innovative teaching, WeChat public number, MOOC.

\section{Introduction}

Open education is a new mode of education, which is based on distance education. In general, open education must follow the basic characteristics of education, and at the same time, it must be guided by practice to reflect its positive significance. Therefore, when implementing open education, it is necessary to start with the characteristics and needs of the education object, and comprehensively consider the development of the school itself. In the context of open education, the reform of Chinese language and literature should carry out targeted reforms with a developmental and changing perspective. The Chinese language and literature major have many years of history in China's college education and is one of the important courses in the study of language and culture. Chinese language has been welcomed by many foreign researchers and international students in recent years, but in China it has gradually disappeared from people's attention. The open education model requires that the teaching of Chinese language and literature changes the current state of mind, and realizes the popularization of education rather than the elite [5]. After collecting the teaching methods of Chinese language and literature majors in the open education mode, the author has caused thinking. Why do we have to implement distance learning in accordance with the traditional classroom teaching model? Nowadays, it is an era of micro-platform and self-enrichment. Why can't we make full use of WeChat public platform, short video and other modes to flip traditional teaching methods. To this end, the thesis puts forward the innovative teaching of Chinese literature based on the WeChat public platform, and combines the Chinese language [6]. According to the specific teaching objects, the corresponding teaching design, teaching practice and teaching effect analysis are carried out. Studies have shown that the new teaching model is effective in helping students master knowledge, experience culture, and improve learning efficiency and interest. Students agree that it is feasible to use this teaching model in Chinese language and literature. 


\section{Theoretical Introduction}

\subsection{The Four-stage Teaching Model of the Jackie Gustin Ring in the Classroom}

In the flip classroom mode built by Jackie Gostin, the operation of "concept exploration", "demo and application" was proposed. The first stage of the venue is mainly the actual classroom. At this stage, students can play games, experiments, and participate in certain activities in the form of group cooperation. In the second stage, students can learn concepts by watching videos, online texts, etc., and ask questions they don't understand. In the third stage, students must complete the construction of meaning. They express their understanding of what they have learned through various means such as voice and video. In the final stage, students must use their imagination and creativity to apply what they have learned to real life, so that knowledge is no longer confined to books or minds. The teaching model constructed by Jackie Gostin overturns the way students learn, encourages students to participate and actively reflect, which greatly mobilizes the initiative of students and helps students improve their ability to analyze and solve problems [7].

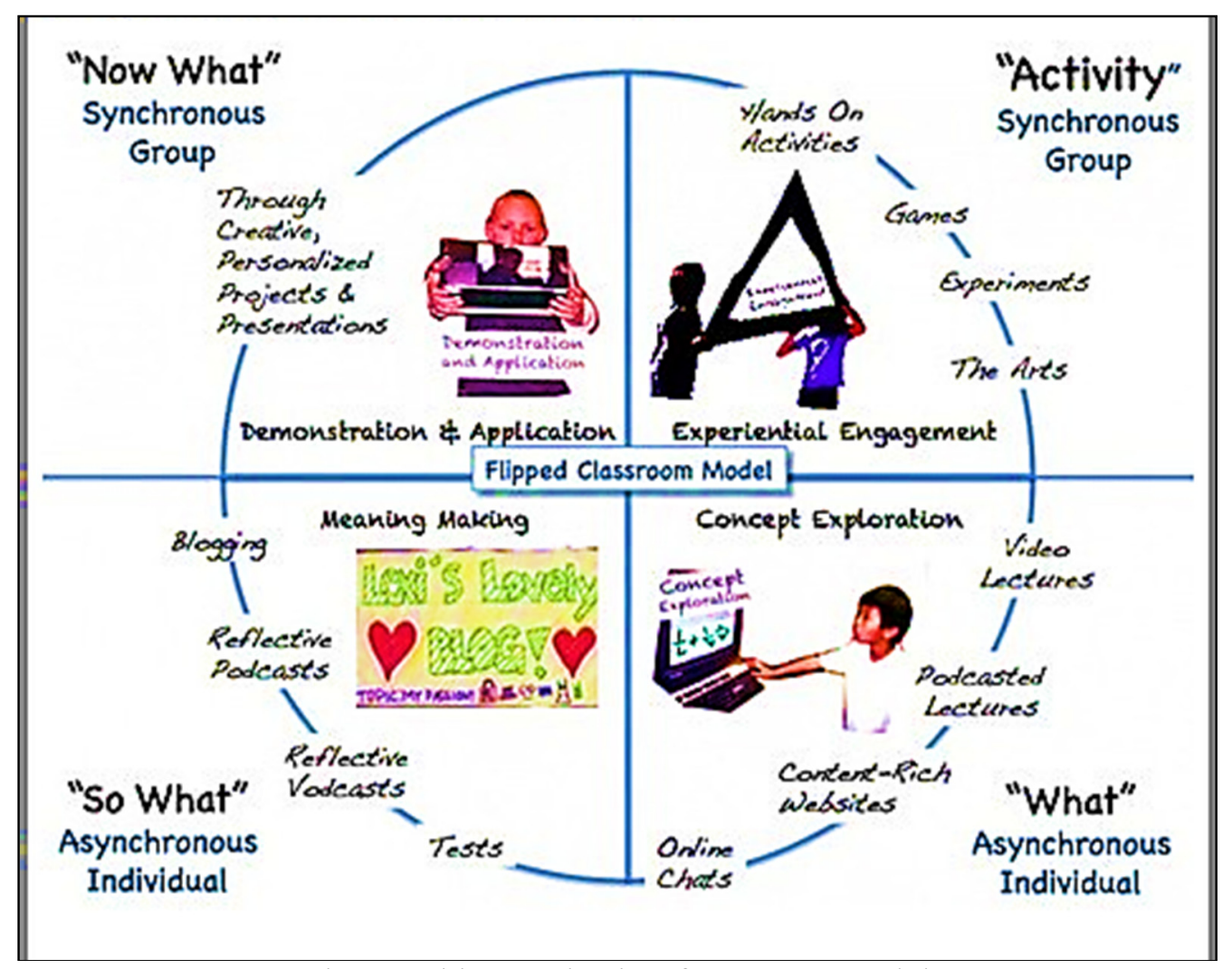

Fig.1 Jackie Gostin ring four-stage model

\subsection{Open Language Education Mode, Chinese Language and Literature Major Combined with Wechat Public Platform Flip Classroom Mode}

The paper proposes a flipping classroom teaching mode for Chinese language and literature majors based on the WeChat public platform. On the basis of the original teaching mode, the teaching model based on the WeChat public platform is combined with the Chinese language and literature major, and detailed operation instructions are given. The paper divides the flipping classroom into three stages: ore-course, in-class, and after-school learning. At the same time, the WeChat public platform is set as a platform for students and teachers to learn (teaching). The paper will focus on this innovative approach to teaching [8]. 


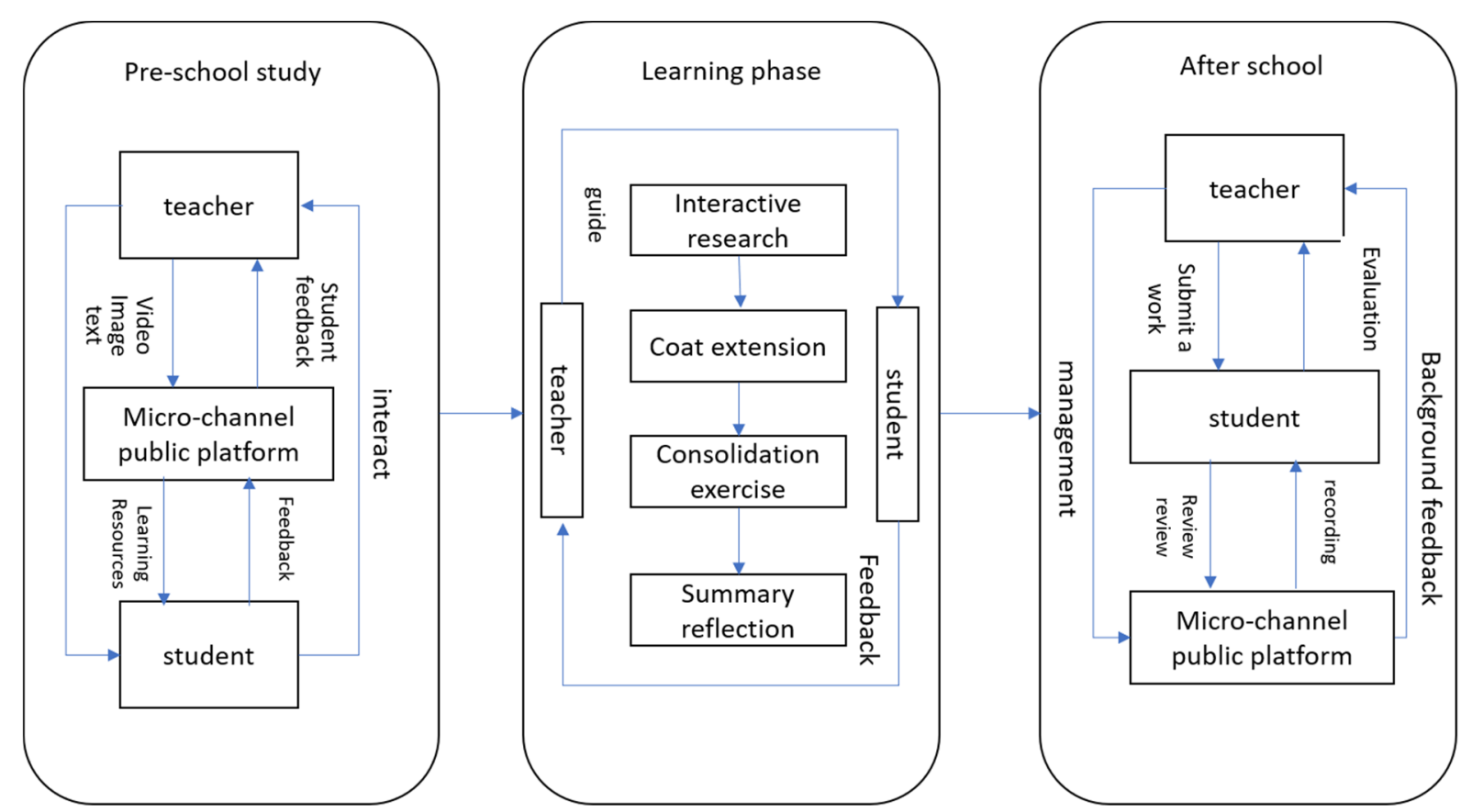

Fig.2 Chinese language and literature classroom teaching mode under the open education model

\section{Feasibility Study on the Open Education Flipping Class of Chinese Language and Literature}

\subsection{Analysis of the Educational Function of Wechat Public Platform}

Tab.1 Analysis of the educational function of the WeChat public platform

\begin{tabular}{|c|c|c|c|}
\hline \multicolumn{2}{|c|}{ function list } & Functional description & Educational application \\
\hline \multirow{3}{*}{ Platform function } & $\begin{array}{l}\text { Operating } \\
\text { platform }\end{array}$ & $\begin{array}{l}\text { IOS, Android, Windows Phone, } \\
\text { Black Berry, Symbian, Microsoft } \\
\text { Windows, Mac OS, Web }\end{array}$ & $\begin{array}{l}\text { Support mobile learning, digital } \\
\text { learning, blended learning, ubiquitous } \\
\text { learning, fragmented learning }\end{array}$ \\
\hline & $\begin{array}{l}\text { Open } \\
\text { platform }\end{array}$ & $\begin{array}{l}\text { Mobile application development, } \\
\text { public account development }\end{array}$ & $\begin{array}{l}\text { Provide an interface to send education } \\
\text { and teaching related content to } \\
\text { designated friends or share to friends }\end{array}$ \\
\hline & $\begin{array}{l}\text { public } \\
\text { platform }\end{array}$ & $\begin{array}{c}\text { Service number, subscription } \\
\text { number }\end{array}$ & $\begin{array}{l}\text { Support function extension, which can } \\
\text { realize group push, auto reply, } \\
\text { subscription push related teaching } \\
\text { materials }\end{array}$ \\
\hline \multirow[t]{2}{*}{$\begin{array}{l}\text { Communication } \\
\text { function }\end{array}$} & $\begin{array}{l}\text { Instant } \\
\text { messaging }\end{array}$ & $\begin{array}{c}\text { Can send text, pictures, voice, } \\
\text { video, support video chat, } \\
\text { location sharing and real-time } \\
\text { intercom }\end{array}$ & $\begin{array}{c}\text { Can be used for discussion and } \\
\text { communication between students and } \\
\text { communication, Q\&A and } \\
\text { personalized guidance between } \\
\text { teachers and students }\end{array}$ \\
\hline & $\begin{array}{l}\text { Group chat } \\
\text { function }\end{array}$ & $\begin{array}{c}\text { Support copulation chat, for } \\
\text { specific functions, see "Function } \\
\text { Description" of "Chat Function" }\end{array}$ & $\begin{array}{c}\text { Support collaborative learning, group } \\
\text { learning, easy discussion and resource } \\
\text { sharing }\end{array}$ \\
\hline \multirow{2}{*}{ Social function } & $\begin{array}{l}\text { Circle of } \\
\text { friends }\end{array}$ & $\begin{array}{l}\text { Can publish graphic information, } \\
\text { share information, "like" and } \\
\text { comment on information points, } \\
\text { and interact with friends }\end{array}$ & $\begin{array}{l}\text { Can realize the release and sharing of } \\
\text { learning resources and learning } \\
\text { experiences, support interactive } \\
\text { comments and learning evaluation }\end{array}$ \\
\hline & Friend add & $\begin{array}{l}\text { Support for finding micro-signals, } \\
\text { QQ friends, contacts, sharing } \\
\text { micro-signals, viewing nearby } \\
\text { people, shaking, drifting bottles }\end{array}$ & $\begin{array}{c}\text { Add friends through multiple channels, } \\
\text { easy to learn group formation, easy to } \\
\text { access learning resources, support and } \\
\text { help }\end{array}$ \\
\hline
\end{tabular}

The WeChat public platform has many practical functions. For smart phone users, using the WeChat public platform is not only a trend, but also a lifestyle choice [9]. Based on the educational 
function of the WeChat public platform, this study analyzes the common functions of the platform function, communication function and social function of the WeChat public platform.

\subsection{Flip the Technical Support Needs of the Classroom}

The student learning process generally includes two stages of "knowledge transfer" and "absorption internalization". The flipping classroom adjusts the "knowledge transfer" phase to the outside of the classroom, and shifts the "knowledge internalization" phase into the classroom, which is the opposite of the traditional classroom. In the flipping classroom mode, students use the teaching videos and related learning materials provided by the teachers to learn knowledge before the class. The teachers are assisted by online guidance. In the classroom, the teachers organize students to discuss and discuss, and provide targeted counseling and answering questions. The teaching method is more conducive to the promotion of students' absorption and internalization of knowledge, which is the advantage of flipping the classroom compared to the traditional classroom.

\section{Implementation}

\subsection{Learning Platform Design}

For users of the WeChat public platform, the first thing they see on the platform is the platform menu. Therefore, in order to design a learning platform, teachers need to make good use of the menu settings of the WeChat public platform. WeChat public platform has a custom menu function. In the custom menu, you can set the menu. Under the menu, you can set the submenu. The submenu can edit the content. There are a total of three levels of menu. In order to rationally lay out the public number layout, let the students stare, the operation is simple and convenient, the teacher visits the WeChat public platform web version, creates a public number called "Teaching Chinese Language and Literature Teaching", and sets "Today" in the custom menu. The two main menus of the course and the teacher. After the two major menus are set, the teacher sets the specific course submenu under the menu "Today's Course", and the submenu publishes the learning task list, the micro lesson video and the practice questions [10]. In addition, you need to set up the "Ask Teacher" menu to remind students to communicate with the teacher in time.

\subsection{Micro-class Production}

In order to avoid the boring and odorless content of the video, the teacher allows the students to watch the short videos related to the excellent courses through the audio-visual method, so that the students can understand the history and cultural knowledge of the course and pave the way for the next step. The micro-course form uses the teacher's teaching process to actually shoot the video. Due to limited conditions, in the choice of production tools, the "HD mobile phone + blackboard + classroom multimedia presentation" shooting mode. Shoot the micro-course video teaching process.

\subsection{Course Design}

The teacher guides the students to discuss the artistic conception during the process of communication. The students actively speak at this stage. Each student presents their own views and fully mobilizes the students' enthusiasm for thinking and exploring the questions. Create a leisurely and enjoyable learning atmosphere. The teacher prompts the students to explain the specific steps and help the students further deepen their impressions.

\subsection{Overall Analysis of After-school Links}

The introductory part of the flipping classroom helps the teacher to further understand the learning knowledge before and during the class. The students can also repeatedly watch the teaching videos and learn repeatedly to deepen their impression of the knowledge they have learned. Through observation, we found that students were not very motivated at this stage, and most of the students did not repeat the viewing and access to learning materials. 


\section{Conclusion}

The new teaching mode has detailed steps and practical operations, and the students have higher acceptance. Based on the WeChat public platform, the implementation steps of the Chinese language and literature course flipping classroom teaching mode are more detailed. Teachers and students have not encountered major obstacles in the teaching practice process, and the operation is feasible. The main reasons for the operation are: the teachers have the basic qualities needed to turn the classroom, the Chinese language and literature teaching objects meet the basic requirements of the flip classroom, the teachers and students are fully equipped, the network is in good condition, the WeChat public platform is convenient, the operation is simple, and the page is intuitive. Under the open education model, the use of the WeChat public platform to implement micro-teaching education has a high teaching efficiency.

\section{References}

[1]. Zhang Jinlei, Zhang Baohui. Application Research of Amplification Learning Concept in Flipping Classroom Teaching. Journal of Distance Education, Vol. 1 (2013) No. 31, p.168-169.

[2]. Wang Hong, Zhao Wei, Sun Lihui, et al. Design of Flipping Classroom Teaching ModelBased on Typical Case Analysis at Home and Abroad. Modern Educational Technology, Vol.8(2013) No. 23, p. 5-10.

[3]. Jiang Lei. Analysis of Teaching Reform of Chinese Language and Literature Major under the Open Education Mode. Language Development, Vol.13 (2012) No. 31, p. 55-56.

[4]. DENG Lihua. Problems and Countermeasures of the Training Mode of Chinese Language and Literature in Open Education of TV University. Digital Users, Vol. 2(2017) No. 23, p.23-25.

[5]. Lin Huiqiong. On the Construction Path of Chinese Language and Literature Specialty in Open Distance Education. Education, Vol. 4 (2008) No. 08, p. 233-237.

[6]. Xu Zhiqiang. Analysis of the Teaching Mode of Chinese Language and Literature Major in the Flipping Classroom. Mangly monthly, Vol. 7(2016) No. 15, p. 78-81.

[7]. Li Haitao. Research on the Training of Classroom Teaching Skills of Chinese Language and Literature Majors in the "Flipping Classroom" Mode. Journal of Pingxiang University, Vol. 4 (2017) No. 34, p. 92-95.

[8]. Yu Minfang. MOOC Path and Strategy of College Literature Course_Reflection on Teaching Based on MOOC Course "The Beauty of Chinese Poetry". Journal of Hebei Agricultural University, Vol. 5 (2015) No.25, p. 87-90.

[9]. Han Menglin. Personalized Instructional Design of Flipping Classroom Teaching Model Taking the Design Color Course as an Example. Teaching and Learning (Higher Education Forum), Vol. 5 (2017) No. 33, p. 115-124.

[10]. Liu Fang. Application Research of Flipping Classroom in College Economic Management Teaching Based on MOOC Mode. Manager, Vol. 3(2017) No. 18, p.15-18. 